\title{
Improved diagnosis of Trichuris trichiura by using a bead-beating procedure on ethanol preserved stool samples prior to DNA isolation and the performance of multiplex real-time PCR for intestinal parasites
}

\author{
MARIA M. M. KAISAR ${ }^{1,2}$, ERIC A. T. BRIENEN ${ }^{2}$, YENNY DJUARDI $^{1}$, \\ ERLIYANI SARTONO ${ }^{2}$, MARIA YAZDANBAKHSH $^{2}$, JACO J. VERWEIJ ${ }^{2} \dagger$, \\ TANIAWATI SUPALI ${ }^{1}$ and LISETTE VAN LIESHOU'T ${ }^{2} *$ \\ ${ }^{1}$ Department of Parasitology, Faculty of Medicine, Universitas Indonesia, Fakarta, Indonesia \\ ${ }^{2}$ Department of Parasitology, Leiden University Medical Center, Leiden, The Netherlands
}

(Received 30 September 2016; revised 19 Fanuary 2017; accepted 20 Fanuary 2017; first published online 14 March 2017)

\begin{abstract}
SUMMARY
For the majority of intestinal parasites, real-time PCR-based diagnosis outperforms microscopy. However, the data for Trichuris trichiura have been less convincing and most comparative studies have been performed in populations with low prevalence. This study aims to improve detection of T. trichuria DNA in human stool by evaluating four sample preparation methods. Faecal samples $(n=60)$ were collected at Flores island, Indonesia and examined by microscopy. Aliquots were taken and a bead-beating procedure was used both on directly frozen stool and on material preserved with $96 \%$ ethanol. PCR on frozen samples showed $40 \%$ to be positive for $T$. trichiura, compared with $45 \%$ positive by microscopy. The percentage positive increased when using ethanol preservation $(45 \cdot 0 \%)$, bead-beating $(51 \cdot 7 \%)$ and a combination $(55.0 \%)$ and all three methods showed significantly higher DNA loads. The various procedures had a less pronounced effect on the PCR results of nine other parasite targets tested. Most prevalent were Ascaris lumbricoides $(\approx 60 \%)$, Necator americanus $(\approx 60 \%)$, Dientamoeba fragilis $(\approx 50 \%)$ and Giardia lamblia $(\approx 12 \%)$. To validate the practicality of the procedure, bead-beating was applied in a population-based survey testing 910 stool samples. Findings confirmed beadbeating before DNA extraction to be a highly efficient procedure for the detection of T. trichiura DNA in stool.
\end{abstract}

Key words: Trichuris trichiura, intestinal parasite, bead-beating, sample preparation, real-time PCR.

\section{INTRODUCTION}

An estimated 1.45 billion people globally are infected with at least one or more of the soil-transmitted helminths (STH). Within this group whipworm (Trichuris trichiura) infects about 450 million people, mostly school age children (Pullan et al. 2014). Although many cases show only mild symptoms or are even asymptomatic, trichuriasis still has significant health consequences. Anaemia and poor nutrition status, especially in children, are partially attributable to chronic $T$. trichiura infections, while heavy worm burdens can result in ulcerative colitis and rectal prolapse (Knopp et al. 2012).

Diagnosis of STH as well as other intestinal parasites has always relied on the classical microscopic examination of stool samples as it is relatively simple to perform and does not require expensive laboratory equipment. However, microscopy is highly observer dependent, therefore lacking the

* Corresponding author: Department of Parasitology, Leiden University Medical Center, Albinusdreef 2 (zone L4-Q) 2300 RC, Leiden, The Netherlands. E-mail: lvanlieshout@1umc.nl

$\dagger$ Current address: Laboratory for Medical Microbiology and Immunology, St. Elisabeth Hospital, Tilburg, The Netherlands. opportunity to perform sufficient quality control. Moreover, the limited sensitivity has relevant consequences when monitoring the impact of mass drug administration as light infections are easily missed, hence population-based cure rates are overestimated (van Lieshout \& Yazdanbakhsh, 2013; Knopp et al. 2014). The widely used Kato-smear-based stool examination for the detection of helminth eggs will miss most of the low-intensity infections and therefore specifically lacks sensitivity when approaching the end of the elimination phase in a control setting (Barda et al. 2015; Utzinger et al. 2015).

As an alternative to microscopy, DNA-based diagnostics have proved for over a decade to out-perform microscopy in the detection of gastro-intestinal parasites (Verweij, 2014). Real-time polymerase chain reaction (PCR) has been shown to be more specific and sensitive than direct parasitological techniques and its (semi) quantitative output also reflects the amount of parasite DNA present (Knopp et al. 2014; Verweij, 2014; Easton et al. 2016). Moreover, within a multiplex format different parasite targets can be detected in a single procedure. An advantage of DNA-based detection methods is the fact that stool samples when directly mixed with a preservative like ethanol, can be stored

Parasitology (2017), 144, 965-974. C Cambridge University Press 2017. This is an Open Access article, distributed under the terms of the Creative Commons Attribution licence (http://creativecommons.org/licenses/by/4.0/), which permits unrestricted re-use, distribution, and reproduction in any medium, provided the original work is properly cited. 
without immediate need of a cold chain (ten Hove et al. 2008). Therefore it is relatively simple to collect samples in remote rural areas and transport them to a central laboratory for further analysis without compromising the quality of the targeted DNA.

Nevertheless, despite its high-throughput screening potentials multiplex real-time PCR has not yet replaced microscopy for the diagnosis of STH in large-scale epidemiological surveys. Undoubtedly this can be explained by a range of logistical and financial challenges, which might be faced when implementing DNA detection-based diagnostics in a low resource laboratory setting. But an additional explanation has been the lack of a more efficient, though simple-to-use procedure to detect $T$. trichiura DNA in human stool samples within a multiplex or multi-parallel real-time PCR context. The most likely explanation for the relatively poor performance of the $T$. trichiura PCR, as seen in several studies, seems to be the robustness of $T$. trichiura eggs, hampering optimal DNA isolation (Verweij \& Stensvold, 2014). Further improvement of the DNA isolation steps is therefore important, because as long as not each of the target helminth species can be diagnosed by the highly sensitive DNA detection-based methodology in combination with a relatively simple-to-use uniform sample-processing procedure, complementary microscopy examination of stool samples will remain indispensable (Wiria et al. 2013; Cimino et al. 2015; Gordon et al. 2015; Meurs et al. 2015).

To optimize DNA extraction for the detection of T. trichiura, several studies have suggested a supplementary bead-beating step proceeding a standard DNA extraction protocol (Andersen et al. 2013; Demeler et al. 2013; Liu et al. 2013; Platts-Mills et al. 2014; Easton et al. 2016). But only one short publication systematically evaluated the effect of bead-beating in relation to the microscopy outcome by comparing different procedures in a stool samples spiked with different concentrations of $T$. trichiura eggs. In this study, bead-beating actually did not result in a higher sensitivity of the T. trichiura PCR (Andersen et al. 2013).

Besides bead-beating, additional heating and centrifugation steps have been introduced specifically to enable efficient extraction of $T$. trichiura DNA (Mejia et al. 2013). Notably, nearly all studies applying these additional procedure showed a PCR-based prevalence of $T$. trichiura below $3 \%$, which obscures the actual beneficial effects of these (Mejia et al. 2013; Cimino et al. 2015; Easton et al. 2016; Llewellyn et al. 2016).

The aim of the current study is to evaluate different methods to improve the detection of T. trichuria DNA in human stool. We therefore compared the effect of a bead-beating procedure prior to DNA extraction in stool samples with and without ethanol preservation. Stool samples were collected at
Nangapanda village, situated in an area highly endemic for STH in Indonesia (Wiria et al. 2013). Samples were tested by multiplex real-time PCR for the presence of $T$. trichiura DNA as well as for nine other intestinal parasite targets and findings were compared with microscopy. In addition, to validate practical aspects of the procedure, beadbeating followed by $T$. trichuria DNA detection was applied in a large-scale population-based survey before and after intense anthelmintic treatment.

\section{MATERIALS AND METHODS}

\section{Study design and sample collection}

Stool samples were obtained from a multidisciplinary community research project named 'Improving the health quality based on health education in Nangapanda sub-district, East Nusa Tenggara', from the University of Indonesia. The study was approved by the ethics committee at the Faculty of Medicine, University of Indonesia with ethics number: $653 / \mathrm{UN} 2 . \mathrm{F} 1 / \mathrm{ETIK} / 2014$. In brief, this project focuses on the identification of factors that might contribute to food-borne diseases in young children living in Nangapanda sub-district, Ende, Flores Island, Indonesia. The study site has been selected partly based on the known high prevalence of STH (Wiria et al. 2013). The study started in January 2014. A total of 400 mothers were recruited together with their child, if within the age range of 1-5 years old. Participants gave written informed or parental consent. Each participant received an appropriate stool container and was asked to provide their fecal sample the following morning. The first 60 stool samples of at least $3 \mathrm{~g}$ were included. This sample size was based on a convenience sample that was limited by budget and personnel. The 60 samples originated from 38 mothers, ranging in age from 20 to 47 years (median 34 years) and 22 children (median age 3 years).

\section{Sample preparation and DNA isolation}

Figure 1 shows the sample preparation procedures used. Within a few hours after collection of the containers, two $25 \mathrm{mg}$ Kato-smears were made and examined within $30-60 \mathrm{~min}$ by two independent microscopists for the presence of helminth eggs. In addition, two aliquots were taken from each stool sample. One aliquot of approximately $1-1.5 \mathrm{~g}$ was stored directly at $-20{ }^{\circ} \mathrm{C}$ and kept frozen during transport. The other aliquot, equal to approximately $0.7 \mathrm{~mL}$ of volume, was mixed thoroughly with $2 \mathrm{~mL}$ of $96 \%$ ethanol by stirring with a wooden stick (ten Hove et al. 2008). These feces-ethanol solutions were initially stored at room temperature for around 4 weeks and thereafter stored and transported at $4{ }^{\circ} \mathrm{C}$. 


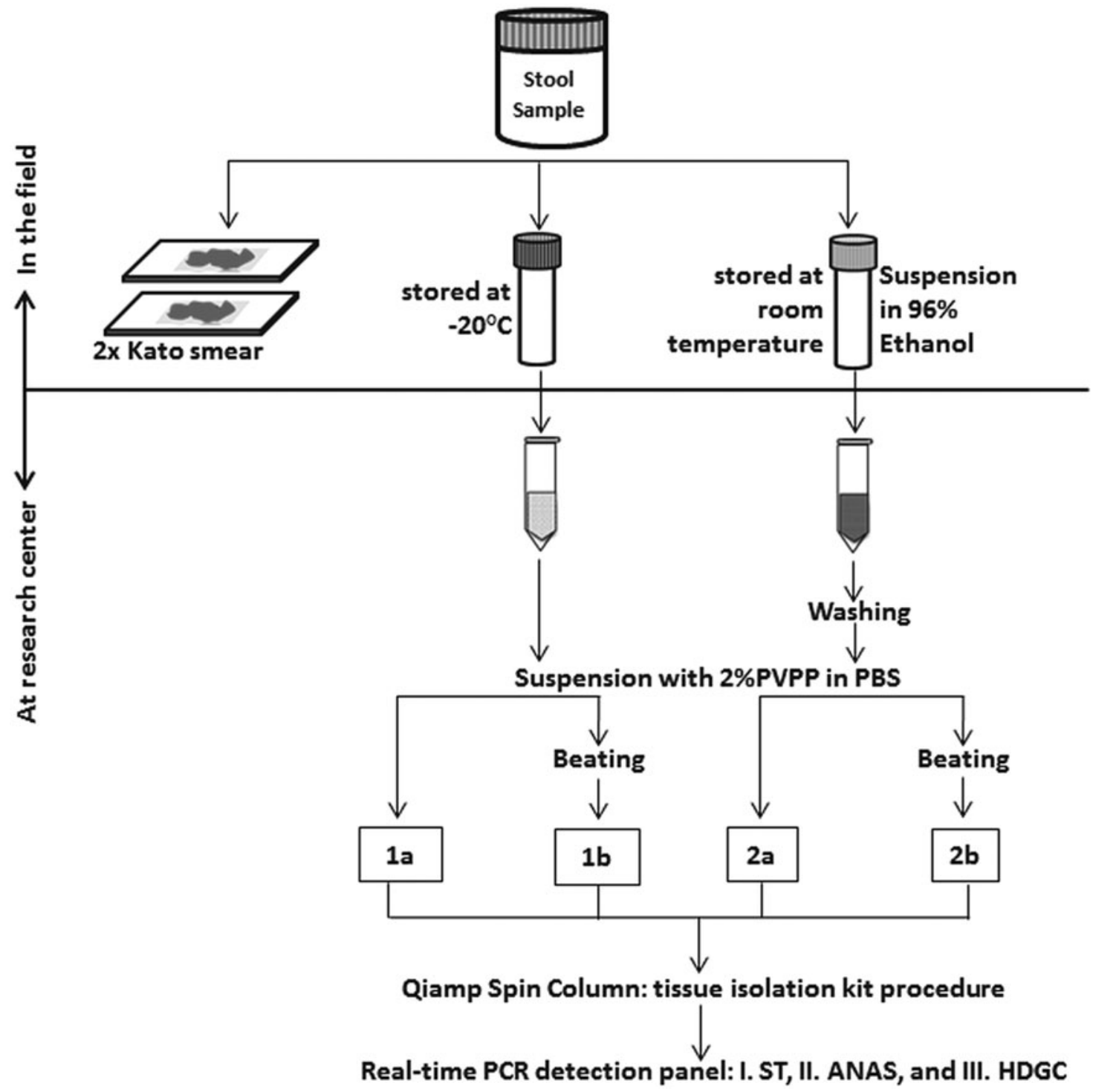

Fig. 1. Flow-chart of the collection, preparations and measurements of 60 stool samples. Each preparation procedure is labelled as: $1 \mathrm{a}=\mathrm{C} \_$PCR: PCR from directly frozen sample; $2 \mathrm{a}=\mathrm{E} \_$PCR: PCR from ethanol preserved samples; $1 \mathrm{~b}=\mathrm{B} \_$PCR: PCR from bead-beating supplemented on frozen sample; 2b=E_B_PCR: PCR from bead-beating supplemented on ethanol-preserved samples. Real-time PCR detection: Panel I=ST (targetting Schistosoma sp. and T. trichiura); Panel II=ANAS (targetting $A$. duodenale, $N$. americanus, $A$. lumbricoides and $S$. stercoralis); Panel III=HDGC (targetting E. histolytica, D. fragilis, G. lamblia and Cryptosporidium spp.).

Upon arrival at the Leiden University Medical Center (LUMC), the Netherlands, a custom-made automated liquid handling station (Hamilton, Bonaduz, Switzerland) was used for washing of samples, DNA isolation and the setup of the PCR plates. A washing step was applied to the preserved samples to remove the ethanol as described previously (ten Hove et al. 2008). Thereafter, both the washed samples and the frozen samples were suspended in $250 \mu \mathrm{L}$ of PBS containing $2 \%$ polyvinylpolypyrrolidone (pvpp) (Sigma, Steinheim, Germany) (Verweij et al. 2009). From each suspension $200 \mu \mathrm{L}$ was transferred to two deep-well plates $(96 \times 2.0 \mathrm{~mL}$ round, Nerbe Plus, Germany). From this point the following codes were used to label each of the four sample preparation procedures: C_PCR, which stands for controls, i.e. DNA extraction was performed on frozen samples without bead-beating; B_PCR, i.e. bead-beating was performed before DNA extraction on frozen samples; E_PCR, i.e. DNA extraction was performed on ethanol preserved samples; and E_B_PCR, bead-beating was performed before DNA extraction on ethanol preserved samples (Fig. 1). For the bead-beating procedure, $0.25 \mathrm{~g}$ of $0.8 \mathrm{~mm}$ garnet bead (Mobio US, SanBio Netherlands) was added to the B_PCR and E_B_PCR suspensions, followed by a beating process for $3 \mathrm{~min}$ at 1800 rotations per minute (rpm) using a homogenization instrument (Fastprep 96, MP Biomedical, Santa Ana California, USA). The choice of garnet bead was based on a small pilot study comparing five different bead types (see 
Supplementary Table S1). DNA extraction was performed using a spin column-based procedure as previously described (Wiria et al. 2010). In each sample, $10^{3}$ plaque-forming unit (PFU) $\mathrm{mL}^{-1}$ Phocin herpes virus-1 (PhHV-1) was included in the isolation lysis buffer, to serve as an internal control.

\section{Parasite DNA detection}

Three different multiplex real-time PCR detection panels were used to detect and quantify parasite specific DNA of six helminth species and four species of intestinal protozoa. Panel I targets Schistosoma sp. and T. trichiura; Panel II targets Ancylostoma duodenale, Necator americanus, Ascaris lumbricoides and Strongyloides stercoralis; Panel III targets Entamoeba histolytica, Dientamoeba fragilis, Giardia lamblia and Cryptosporidium spp. The sequences of primers and probes and the setup of the PCR were based on published information and are also summarized in the Supplementary Table S2 and S3 (Niesters, 2002; Verweij et al., 2003a, b; Verweij et al., 2004; Verweij et al., 2007a, b; Jothikumar et al., 2008; Obeng et al., 2008; Wiria et al., 2010; Hamid et al., 2011; Liu et al., 2013). Amplification, detection and analysis were performed using the CFX real-time detection system (Bio-Rad laboratories). Negative and positive control samples were included in each PCR run. Cycle threshold (Ct) value results were analysed using Bio-Rad CFX software (Manager V3.1.1517-0823). The Ct-value represents the amplification cycle in which the level of fluorescent signal exceeds the background fluorescence $\left(10^{2}\right.$ Relative Fluorescents Units), reflecting the parasite-specific DNA load in the sample tested. The amplification of individual samples was considered to be hampered by inhibitory factors if the expected Ct-value of 31 in the PhHV-specific PCR was increased by more than $3 \cdot 3$ cycles. The $\mathrm{PhHV}$ PCR showed no significant reduction in $\mathrm{Ct}$ value as a result of the newly introduced sample preparation procedures. For each parasite-specific target, DNA loads were arbitrarily categorized into the following intensity groups: low $(35 \leqslant \mathrm{Ct}<50)$, moderate $(30 \leqslant$ $\mathrm{Ct}<35)$ and high $(\mathrm{Ct}<30)$ (Pillay et al. 2014).

\section{Application stage}

An additional set of 910 stool samples was used to validate the practicality of $T$. trichiura DNA detection, in particular for the purpose of large-scale population-based surveys. Details of the study design have been published in the study protocol (Tahapary et al. 2015). In brief, faecal samples were collected at Nangapanda, on Flores Island, Indonesia, from 455 adults, age 16-83 years old (median 45 years), before and after a 1 -year period of three monthly household treatments on three consecutive days with a single dose of $400 \mathrm{mg}$ albendazole. Following microscopic examination of duplicate $25 \mathrm{mg}$ Kato-smears, an aliquot of each stool sample was frozen within $24 \mathrm{~h}$ after collection and transferred to the Netherlands for laboratory analysis. For logistical reasons, explained in the discussion paragraph, it was decided in this study not to use ethanol preservation of stool samples. DNA isolation and detection of T. trichiura DNA was performed as described above according to the $\mathrm{B}_{-}$PCR procedure. Pre- and post-treatment samples were tested pairwise, blinded from microscopy data.

\section{Data management and statistical analysis}

All collected data were exported to the SPSS $20 \cdot 0$ (IBM, Chicago, IL) for statistical analysis and to Graph Pad 6 for visualization. Negative samples were recoded into an arbitrary value, i.e. $0 \cdot 5$ for egg counts and $\mathrm{Ct} 50$ for PCR. Microscopy results were expressed as eggs per gram (EPG) of stool. Descriptive analysis was used to characterise the outcome of each sample preparation procedure. The percentages of positives were compared by their 95\% confidence intervals $(95 \%$ CI $)$. The Wilcoxon signed-rank test was used to analyse a difference in median Ct-value between C_PCR (DNA extraction performed on frozen samples without bead-beating) and each of the alternative preparation procedures. This analysis was performed on those samples positive for at least one of the two indicated procedures and only for those parasite targets with nine or more positive samples. The Spearman's rho $(\rho)$ value was used to indicate the strength of correlation between egg output (EPG) and DNA load (Ct-value) for T. trichiura and $A$. lumbricoides, as only these two have speciesspecific microscopy as well as PCR data available. Samples negative for both procedures were excluded in the statistical analysis. The McNemar test was used to compare paired proportions of microscopy and PCR detected T. trichiura cases in the population-based survey. A $P$-value $<0.05$ was considered to be statistically significant.

\section{RESULTS}

\section{Intestinal parasite detection}

Table 1 shows parasite detection rates as determined by microscopy and real-time PCR following each of the four fecal sample preparation procedures. None of the samples were positive for Schistosoma sp., $S$. stercoralis or E. histolytica. Based on microscopy Ascaris lumbricoides (60\%) was the most prevalent STH found, followed by hookworm $(46 \cdot 7 \%)$ and T. trichiura $(45 \cdot 0 \%)$. The real-time $\mathrm{PCR}$ results from frozen samples (C_PCR) showed a lower percentage of $T$. trichiura positives $(40 \cdot 0 \%)$ compared to the Kato-smear $(45 \cdot 0 \%)$, while bead-beating 


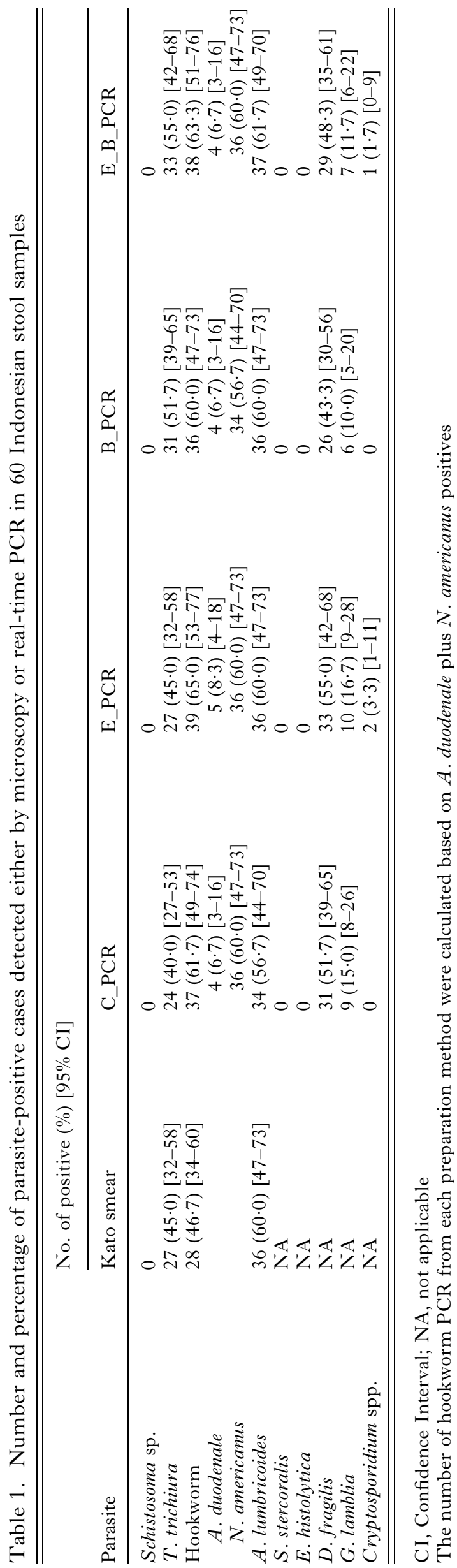

(B_PCR) and the bead-beating on ethanol preserved samples (E_B_PCR) resulted in higher detection rates compared to microscopy, although the 95\% CI did overlap. Using real-time PCR for the detection of hookworm, the number of positive cases ranged from $60 \cdot 0$ to $65.0 \%$, with minor differences between the different sample preparation procedures. Necator americanus was found to be the dominant hookworm species. For $A$. lumbricoides the C_PCR procedure showed somewhat lower detection levels than microscopy, E_PCR, B_PCR and E_B_PCR, but none of the differences were significant. For intestinal protozoa the most prevalent species was $D$. fragilis $(55 \cdot 0 \%)$ followed by $G$. lamblia $(16 \cdot 7 \%)$ and for both species the highest detection rates were found with the E_PCR procedure.

\section{Stool parasite DNA load}

Figure 2 displays the distribution of the PCR Ctvalues for the five most common parasite targets for each of the sample preparation procedure, while Table 2 shows the comparison between the median Ct values. For T. trichiura, the C_PCR procedure showed low DNA loads $(\mathrm{Ct} \geqslant 35)$ in the majority of 24 PCR-positive samples. High DNA loads $(\mathrm{Ct}<30)$ were detected in 10 of 31 PCR positives $(32 \cdot 3 \%)$ after bead-beating on frozen samples (B_PCR) and in 20 of 33 PCR positives $(75.8 \%)$ after bead-beating on ethanol preserved samples (E_B_PCR). All three modified sample preparation procedures showed significant higher $T$. trichiura DNA levels compared with the control procedure (Table 2).

For $N$. americanus most PCR positive samples were categorized as having moderate to high DNA loads $(\mathrm{Ct}<35)$ in all four sample preparation procedures (Fig. 2). The bead-beating procedure on ethanol preserved samples (E_B_PCR) resulted in significantly higher $N$. americanus DNA levels compared to the controls. In contrast, when the beadbeating procedure was applied on frozen samples (B_PCR) N. americanus DNA levels were significantly lower compared with the controls (Table 2).

DNA loads in A. lumbricoides PCR-positive samples were mainly categorized as high (Fig. 2). This was most prominent in the E_B_PCR group with 35 of 37 PCR-positive samples (95.0\%) showing a $\mathrm{Ct}$ below 30 . The $A$. lumbricoides DNA load was significantly higher when comparing the E_B_PCR procedure with the control procedure, while no difference was seen for the two other sample preparation procedures (Table 2).

Using the bead-beating procedure (B_PCR) both the $D$. fragilis $\mathrm{PCR}$ and the $G$. lamblia $\mathrm{PCR}$ showed lower numbers of PCR-positive samples, as well as reduced DNA loads compared with the frozen controls (Fig. 2, Table 2). The same trend was seen when samples were preserved in ethanol. 
DNA load distribution

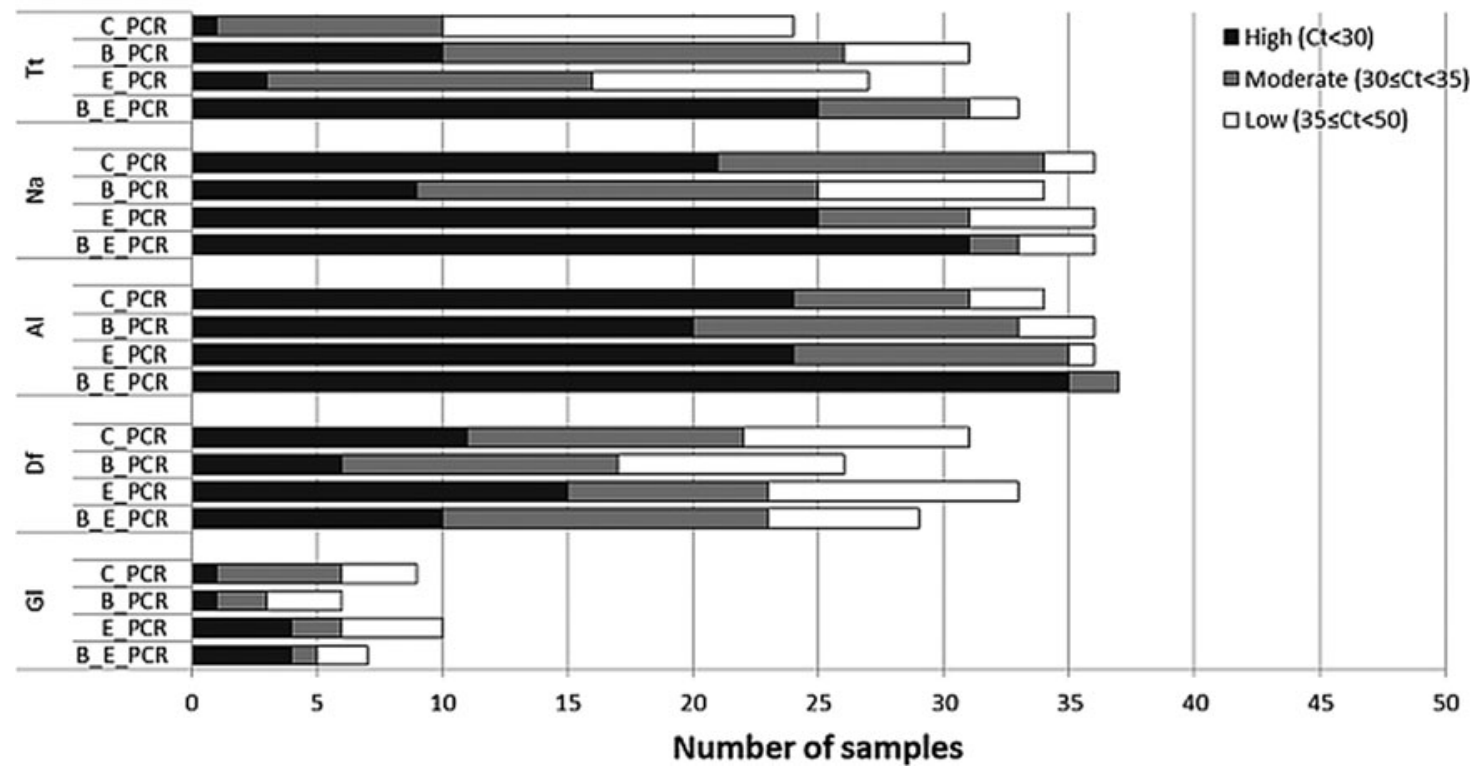

Fig. 2. DNA load distribution of five most prominent intestinal parasites using four different preparation procedures on 60 stool samples. PCR results following the sample preparation procedure: C_PCR $=$ directly frozen sample; $E \_P C R=$ ethanol-preserved sample; B_PCR = bead-beating supplemented on frozen sample; E_B_PCR = bead-beating supplemented on ethanol-preserved samples. Tt, T. trichiura; Na, N. americanus; Al, A. lumbricoides; Gl, G. lamblia; Df, D. fragilis.

Table 2. Comparison of median cycle threshold $(\mathrm{Ct})$ values between sample preparations procedures for the detected intestinal parasites

\begin{tabular}{|c|c|c|c|c|c|c|c|c|c|c|c|c|}
\hline \multirow{2}{*}{$\frac{\text { Species }}{\text { T. trichiura }}$} & \multicolumn{2}{|c|}{$\begin{array}{l}\text { Ct C_PCR } v s \\
\text { E_PCR }\end{array}$} & \multirow{2}{*}{$\begin{array}{l}N \\
29\end{array}$} & \multirow{2}{*}{$\begin{array}{l}P \text {-value } \\
* *\end{array}$} & \multicolumn{2}{|c|}{$\begin{array}{l}\text { Ct C_PCR vs } \\
\text { B_PCR }\end{array}$} & \multirow{2}{*}{$\begin{array}{l}N \\
34\end{array}$} & \multirow{2}{*}{$\begin{array}{l}P \text {-value } \\
* * *\end{array}$} & \multicolumn{2}{|c|}{$\begin{array}{l}\text { Ct C_PCR vs } \\
\text { E_B_PCR }\end{array}$} & \multirow{2}{*}{$\begin{array}{l}N \\
35\end{array}$} & \multirow{2}{*}{$\frac{P \text { value }}{* * *}$} \\
\hline & $35 \cdot 35$ & $33 \cdot 82$ & & & $36 \cdot 29$ & $32 \cdot 02$ & & & $36 \cdot 38$ & $28 \cdot 53$ & & \\
\hline N. americanus & $29 \cdot 30$ & $28 \cdot 75$ & 37 & NS & $28 \cdot 86$ & $32 \cdot 65$ & 36 & *** & $29 \cdot 30$ & $26 \cdot 53$ & 37 & *** \\
\hline A. lumbricoides & $28 \cdot 11$ & 28.95 & 36 & NS & $28 \cdot 11$ & $29 \cdot 55$ & 36 & NS & $28 \cdot 21$ & $24 \cdot 77$ & 37 & **** \\
\hline D. fragilis & $32 \cdot 16$ & $30 \cdot 21$ & 33 & **** & $32 \cdot 16$ & $34 \cdot 26$ & 31 & **** & $32 \cdot 16$ & $31 \cdot 53$ & 32 & NS \\
\hline G. lamblia & $34 \cdot 40$ & $34 \cdot 33$ & 10 & NS & $34 \cdot 23$ & $35 \cdot 87$ & 9 & ** & $34 \cdot 40$ & $36 \cdot 49$ & 10 & NS \\
\hline
\end{tabular}

NS, not significant.

$P$ value: $*<0 \cdot 05 ; * *<0 \cdot 01 ; * * *<0 \cdot 001$

Inclusion criteria: If result from one of the indicated procedure was positive. Analysis was done using Wilcoxon matchedpair rank test. C_PCR=PCR resulted from directly frozen sample; E_PCR=PCR resulted from ethanol preserved samples; B_PCR=PCR resulted from bead-beating supplemented on frozen sample; E_B_PCR=PCR resulted from bead-beating supplemented on ethanol-preserved samples.

Figure 3 shows the association between parasite DNA levels, represented by PCR Ct-value, and faecal egg count for $T$. trichiura and A. lumbricoides. Trichuris trichiura egg counts ranged from 60 to $33.740 \mathrm{epg}$ (median $780 \mathrm{epg}$ ) and $A$. lumbricoides egg counts ranged from 760 to 226.520 epg (median $19 \cdot 330 \mathrm{epg}$ ). For each of the four sample preparation procedures a positive correlation was found. For $T$. trichiura, the highest correlation coefficients were seen with the E_PCR procedure (Fig. 2B; $\rho=0 \cdot 597$, $n=32, \quad P<0.001)$ and the E_B_PCR procedure (Fig. 2D; $\rho=0.727, n=33, P<0 \cdot 001$ ). For A. lumbricoides, the highest correlation coefficients were seen when using the B_PCR procedure (Fig. 2G; $\rho=$ $0.642, n=37, P<0.001)$ and the E_B_PCR procedure (Fig. $2 \mathrm{H} ; \rho=0 \cdot 645, n=38, P<0 \cdot 001$ ).

\section{Application in an epidemiological survey}

Figure 4 shows a comparison between the prevalence and intensity of T. trichiura infection determined by microscopy and by PCR using the bead-beating procedure (B_PCR) in a large-scale population-based study. Based on microscopy $21 \cdot 5 \%$ of this adult population $(n=455)$ was found to be positive for T. trichiura (range 20-5360 epg) prior to treatment, 

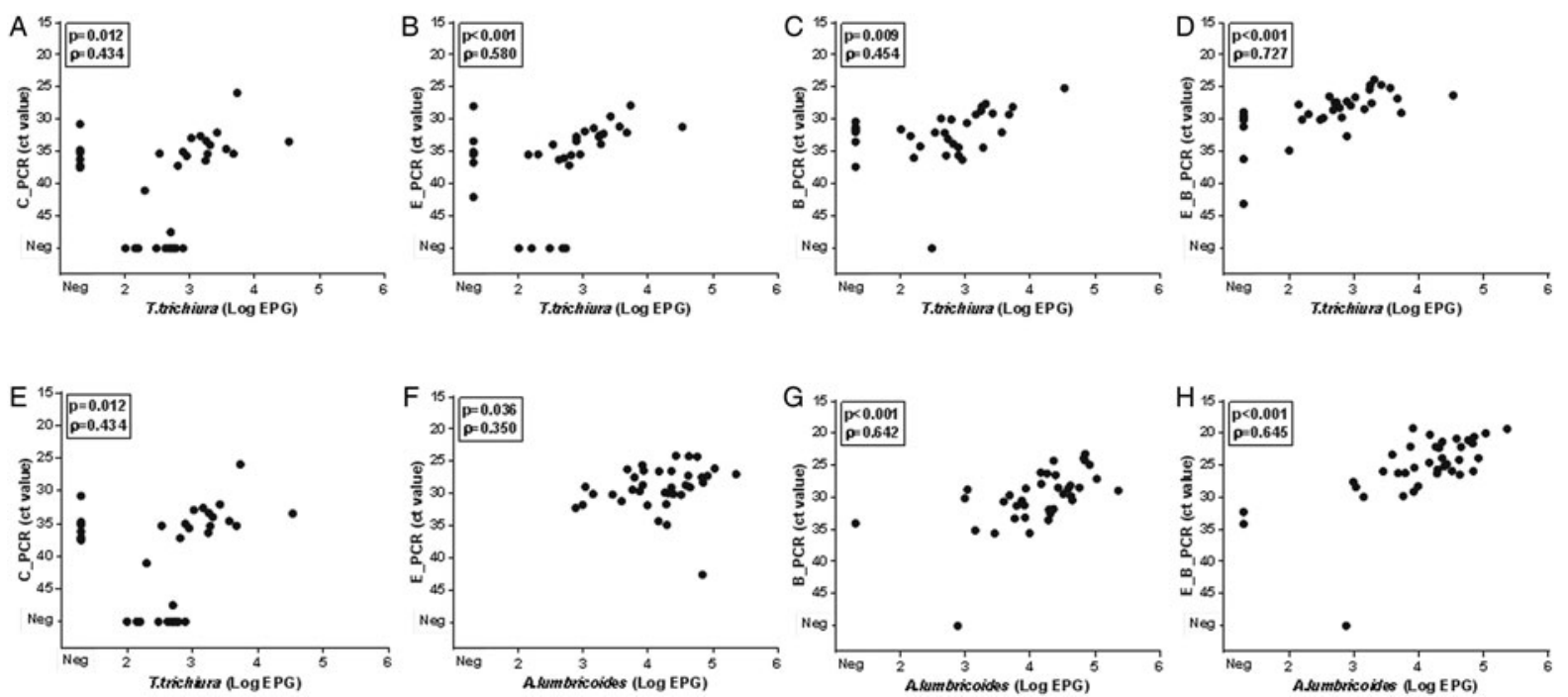

Fig. 3. Association between egg output (Log EPG) and DNA load (Ct value) for T. trichiura (A-D) and A. lumbricoide $(\mathrm{E}-\mathrm{H})$. PCR results following the sample preparation procedure: C_PCR $=$ directly frozen sample; E_PCR $=$ ethanolpreserved sample; B_PCR = bead-beating supplemented on frozen sample; E_B_PCR = bead-beating supplemented on ethanol-preserved samples. Samples negative for both microscopy and real-time PCR were excluded in the statistical analysis.

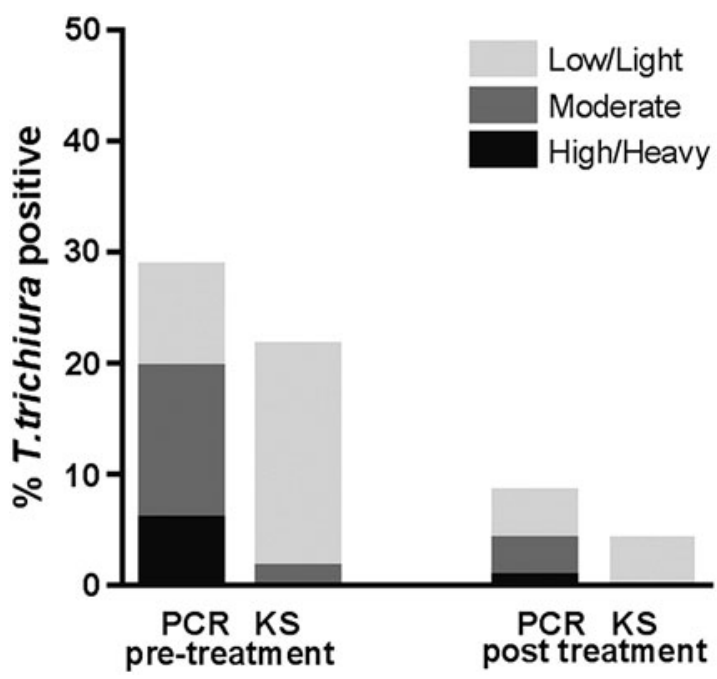

Fig. 4. Prevalence and intensity of T. trichiura detected by PCR and Kato smear (KS) in 455 individuals before and 1 year after intense albendazole treatment. $\mathrm{Ct}$ values generated from real-time PCR were divided into three groups: high DNA load $=\mathrm{Ct}<30$, moderate DNA Load $=$ $30 \leqslant \mathrm{Ct}<35$ and low DNA load $=35 \leqslant \mathrm{Ct}<50$. EPG is calculated from Kato smear detection and divided into three categories based on WHO criteria: heavy $-=\geqslant 10,000$, moderate $-=1000-9999$, and light-infection $=1-999$.

with 91 of the 98 positives showing $<1000$ epg and a median egg count of 100 epg. Following a year of intense anthelmintic treatment, eggs of T. trichiura were seen in 18 individuals $(4 \cdot 0 \%)$ with egg counts ranging from 20 to 400 epg (median 40 epg). Significantly more cases were detected by PCR than by microscopy, both before $(28 \cdot 8 \%)$ and after $(8 \cdot 4 \%)$ repeated rounds of albendazole treatment $(P=0 \cdot 001)$.

\section{DISCUSSION}

Molecular methods like real-time PCR are increasingly used in the diagnosis of intestinal helminths (Verweij and Stensvold, 2014; O'Connell and Nutman, 2016). However, large-scale application of DNA detection procedures seems to be impaired, partly by the fact that the standard DNA extraction methods are not sufficient to release DNA from $T$. trichiura eggs (Demeler et al. 2013). The present study aimed to identify a simple-to-use sample preparation procedure which could replace our previous standard method of stool DNA isolation, thereby increasing the PCR detection rate of T. trichiura-positive cases without uniformly changing the outcome of PCRs targeting other stool parasites.

In the pre-phase of the study, several mechanical procedures (e.g. extensive heating, vortexing, blending and sonication), chemical procedures (e.g. alkaline supplementation, adding of lyticase, achromopeptidase or a higher amount of proteinase $\mathrm{K}$ ) and a number of combinations were evaluated, to see which method performed best to enhance the release of DNA from T. trichiura eggs, but none of them was very successful (data not shown). Better results were seen by the introduction of a bead-beating step, which facilitates the breakdown of the proteinaceous cellular wall, thereby making the DNA accessible (Verollet, 2008; Demeler et al. 2013). Several beads types of different manufacturers were compared and although tested in a small pilot only; differences were seen between the type of beads used (Supplementary Table S1). Based on these findings garnet beads were selected for the further evaluation of the procedures. 
Although the use of bead-beating to facilitate helminth DNA isolation has been mentioned in several publications, details of the performed procedures are mostly limited or even lacking. At most a comparison is made with the number of cases detected by PCR $v$ s the number of cases detected by microscopy (Liu et al., 2013, 2016; Taniuchi et al., 2013; PlattsMills et al., 2014; Easton et al., 2016). For example, in a study performed on 400 unpreserved stool samples collected from 13-month-old children in Ecuador, 3\% of the samples were positive for T. trichiura by PCR compared to $0.75 \%$ positive cases by microscopy (Mejia et al. 2013). In this study, additional heating and centrifugation steps were introduced specifically to enable efficient extraction of $T$. trichiura DNA, but no details have been given and the overall low prevalence of $T$. trichiura makes it difficult to judge the importance of these additional procedures. Moreover, no adequate internal control was implemented to assess potential inhibition during DNA isolation and detection (Mejia et al. 2013).

To our knowledge, Andersen and colleagues are the only group to have published details on the effect of adding beads on the detection of T. trichiura DNA by real-time PCR (Andersen et al. 2013). In this study, three different types of beads, namely glass, garnet and zirconium, were evaluated. Beadbeating was compared with vortexing in the presence of beads. The authors concluded that glass beads were not very practical due to the increased risk of clotting of the tips and that none of the evaluated procedures increased the DNA yield from eggs of T. trichiura (Andersen et al. 2013). However, these findings have been based only on a stool sample artificially spiked with helminth eggs and on a single $T$. trichiura-positive clinical sample.

In the current study, 60 stool samples have been collected from a region in Indonesia known to be highly endemic for STH. This high transmission level was confirmed by the detection of $T$. trichiura eggs in $45 \%$ of the stool samples after performing a duplicate $25 \mathrm{mg}$ Kato-smear examination. However, egg excretion was not correspondingly high in this population with less than half of the positive samples showing more than 1000 epg. Despite the low intensity, this collection of stool samples was regarded as highly suitable for comparing different sample preparation procedures, noting that the majority of studies applying DNA detection-based diagnostic procedures work with a PCR-based prevalence of T. trichiura below 3\% (Mejia et al. 2013; Cimino et al. 2015; Easton et al. 2016; Llewellyn et al. 2016). In addition, the presented collection of stool samples showed high levels of co-infections with other parasites, both helminths and protozoa, so the effect of different sample preparation procedures could be evaluated as well on DNA detection of $N$. americanus, A. lumbricoides, D. fragilis and G. lamblia.
Similarly to our previous, though unpublished, findings on stool samples which have been frozen only, the number of $T$. trichiura PCR-positive cases was lower than the number of microscopypositive cases if no additional sample preparation procedures were applied. Indeed, without the addition of bead-beating the DNA yields of T. trichiura were generally low, with a minority of samples showing a Ct-value below 30. This in contrast to the effect of bead-beating, in particular on ethanol preserved samples, which resulted in the detection of additional helminth-positive cases. Naturally the yield of $T$. trichiura DNA was also found to be substantially higher. The actual mechanism explaining why the addition of ethanol preservation resulted in higher DNA loads detected is not completely clear. The opposite might have been expected as the addition of ethanol requires a washing step, which discharges any free DNA present in the sample. The beneficial effect of combining beadbeating with ethanol preservation was found to be most distinct for the helminth species, in particular for T. trichiura, and not for the protozoa, suggesting the effect to be parasite specific.

Ethanol is widely used as a preservative of biological samples, including fecal material, when nucleic acidbased testing is needed and it was introduced several years ago to facilitate molecular diagnosis of helminth infections in remote populations where no cold-chain is available (ten Hove et al. 2008). Despite the evident advantages of ethanol preservation shown in this study, we do not advocate the routine use of ethanol for all epidemiological studies dealing with stool collection. Three disadvantages of ethanol preservation have led to this new policy. Firstly, based on our experience in a number of population-based surveys, we noticed that the mixing of stool and ethanol in a field setting can be a critical process. Not only the ratio between the fecal material and the preservative is crucial, but the mixing must be thorough otherwise proper preservation will not take place. In case no vortex is available, this should be done by thoroughly stirring with a wooden stick. Secondly, the tubes should be well sealed to prevent leakage during transportation. Finally, the addition of a preservative will make the DNA extraction procedure more laborious and therefore more expensive as the ethanol has to be washed away before actual DNA extraction can proceed. This washing is an additional step in the sample handling procedure which increases the overall risk of human error, in particular if no automated sampling system is available.

In the past, we have encountered errors resulting from each of the three points mentioned above, resulting in the loss of samples for molecular diagnosis, despite detailed instructions to field teams. In the case that no aliquots have been frozen and no supplementary microscopy has been performed, the loss of samples due to inappropriate preservation could be 
devastating. For these reasons we commonly advise our collaborators to directly freeze the samples whenever a proper cold-chain can be guaranteed or otherwise be extremely cautious concerning the point discussed above.

Because of the these practical limitations of ethanol preservation, direct freezing of stool samples has been applied in a recently performed survey on Flores Island, Indonesia, studying the effect of three monthly household treatments with albendazole (Tahapary et al. 2015). Based on microscopy only, the prevalence of $T$. trichiura was found to be $21 \cdot 5 \%$ at baseline, and with a median egg count of $100 \mathrm{epg}$, intensity of infection was already low before the intervention started. The relatively narrow range in egg excretion in this population probably explains why no correlation was found between the intensity of infection based on microscopy and the DNA load as determined by realtime PCR (data not shown). Following a year of intense treatment, a clear reduction was seen in the number of $T$. trichiura-positive cases, both based on microscopy and on DNA detection. Still, around twice as many $T$. trichiura-positives cases were detected by PCR than by microscopy, confirming the higher sensitivity of molecular diagnosis assuming appropriate DNA isolation procedures have been performed (Verweij, 2014; van Lieshout and Roestenberg, 2015).

Our results overall illustrate that relatively minor differences in sample handling procedures can influence the output of real-time PCR. Consequently, comparison of studies, in particular when evaluating intensity of infections, should be interpreted with great care, especially if molecular testing has been performed in different laboratories or procedures have been changed over-time. The use of a standard curve, by adding genomic DNA at different concentrations or plasmids constructed to match the same target sequence, gives the impression that PCR yields standard results. But this does not allow for the effect of different isolation procedures. More progress is expected from defining an internationally recognized standard based on a fixed number of eggs per volume of stool.

In conclusion, the present findings confirm that a bead-beating procedure prior to DNA extraction increases the $T$. trichiura DNA yield in human faecal samples. Moreover, in combination with ethanol preservation this effect is most pronounced and also improves the detection rate of N. americanus and A. lumbricoides. Although ethanol preservation in itself has a positive effect, it also imposes several practical limitation. The effect of bead-beating on the detection of intestinal protozoa does not seem to be as uniform. Therefore bead-beating should be implemented with some caution, in particular when detecting $D$. fragilis in non-preserved samples. The general finding that sample handling procedures significantly influence detected DNA yield illustrates the potential impact of well-defined sample handling procedures and confirms the importance of standardisation. Exchange of proficiency panels between centralised reference laboratories seems an essential step in further harmonisation of molecular diagnosis of intestinal helminths.

\section{SUPPLEMENTARY MATERIAL}

The supplementary material for this article can be found at https://doi.org/10.1017/S0031182017000129.

\section{ACKNOWLEDGEMENTS}

We thank all participants involved in this study as well as the team of the helminthology division, Department of Parasitology, Faculty of Medicine, Universitas Indonesia for their excellent help in samples collection and Katosmear examination. We also acknowledge the SUGARspin team (http://sugarspin.org/), in particular Dicky Tahapary and Karin de Ruiter for their contributions. Finally, we thank the students of the Department of Parasitology, LUMC, who were involved in the project and assisted in the laboratory analysis of the stool samples.

\section{F INANCIAL SUPPORT}

This study was funded by the Prof Dr P. F. C. Flu Foundation; The Royal Netherlands Academy of Arts and Science (KNAW), Ref 57-SPIN3-JRP and the Universitas Indonesia (Research Grant BOPTN 2742/ H2.R12/HKP.05.00/2013). The authors would also like to thank The Indonesian Directorate General of Higher Education (DIKTI) for providing a $\mathrm{PhD}$ scholarship.

\section{REFERENCES}

Andersen, L. O., Roser, D., Nejsum, P., Nielsen, H. V. and Stensvold, C. R. (2013). Is supplementary bead beating for DNA extraction from nematode eggs by use of the NucliSENS easyMag protocol necessary? Fournal of Clinical Microbiology 51, 1345-1347.

Barda, B., Keiser, J. and Albonico, M. (2015). Human trichuriasis: diagnostics update. Current Tropical Medicine Reports 2, 201-208.

Cimino, R. O., Jeun, R., Juarez, M., Cajal, P.S., Vargas, P., Echazu, A., Bryan, P. E., Nasser, J., Krolewiecki, A. and Mejia, R. (2015). Identification of human intestinal parasites affecting an asymptomatic peri-urban Argentinian population using multi-parallel quantitative real-time polymerase chain reaction. Parasites \& Vectors 8, 380.

Demeler, J., Ramunke, S., Wolken, S., Ianiello, D., Rinaldi, L., Gahutu, J. B., Cringoli, G., von Samson-Himmelstjerna, G. and Krucken, J. (2013). Discrimination of gastrointestinal nematode eggs from crude fecal egg preparations by inhibitor-resistant conventional and real-time PCR. PLoS ONE 8, e61285.

Easton, A.V., Oliveira, R.G., O'Connell, E. M., Kepha, S., Mwandawiro, C.S., Njenga, S. M., Kihara, J. H., Mwatele, C., Odiere, M. R., Brooker, S. J., Webster, J.P., Anderson, R. M. and Nutman, T. B. (2016). Multi-parallel qPCR provides increased sensitivity and diagnostic breadth for gastrointestinal parasites of humans: field-based inferences on the impact of mass deworming. Parasites $\&$ Vectors $\mathbf{9}, 38$. Gordon, C. A., McManus, D.P., Acosta, L.P., Olveda, R.M., Williams, G. M., Ross, A. G., Gray, D. J. and Gobert, G. N. (2015). Multiplex real-time PCR monitoring of intestinal helminths in humans reveals widespread polyparasitism in Northern Samar, the Philippines. International Yournal for Parasitology 45, 477-483.

Hamid, F., Wiria, A.E., Wammes, L. J., Kaisar, M. M., Lell, B., Ariawan, I., Uh, H.W., Wibowo, H., Djuardi, Y., Wahyuni, S., Schot, R., Verweij, J.J., van Ree, R., May, L., Sartono, E., 
Yazdanbakhsh, M. and Supali, T. (2011). A longitudinal study of allergy and intestinal helminth infections in semi urban and rural areas of Flores, Indonesia (ImmunoSPIN Study). BMC Infectious Diseases 11,83 .

Jothikumar, N., da Silva, A. J., Moura, I., Qvarnstrom, Y. and Hill, V.R. (2008). Detection and differentiation of Cryptosporidium hominis and Cryptosporidium parvum by dual TaqMan assays. Fournal of Medical Microbiology 57, 1099-1105.

Knopp, S., Steinmann, P., Keiser, J. and Utzinger, J. (2012). Nematode infections: soil-transmitted helminths and trichinella. Infectious Disease Clinics of North America 26, 341-358.

Knopp, S., Salim, N., Schindler, T., Karagiannis Voules, D. A., Rothen, J., Lweno, O., Mohammed, A.S., Singo, R., Benninghoff, M., Nsojo, A. A., Genton, B. and Daubenberger, C. (2014). Diagnostic accuracy of Kato-Katz, FLOTAC, Baermann, and PCR methods for the detection of light-intensity hookworm and Strongyloides stercoralis infections in Tanzania. American Fournal of Tropical Medicine and Hygiene 90, 535-545.

Liu, J., Gratz, J., Amour, C., Kibiki, G., Becker, S., Janaki, L., Verweij, J.J., Taniuchi, M., Sobuz, S. U., Haque, R., Haverstick, D. M. and Houpt, E. R. (2013). A laboratory-developed TaqMan Array Card for simultaneous detection of 19 enteropathogens. Fournal of Clinical Microbiology 51, 472-480.

Liu, J., Gratz, J., Amour, C., Nshama, R., Walongo, T., Maro, A., Mduma, E., Platts-Mills, J., Boisen, N., Nataro, J., Haverstick, D. M., Kabir, F., Lertsethtakarn, P., Silapong, S., Jeamwattanalert, P., Bodhidatta, L., Mason, C., Begum, S., Haque, R., Praharaj, I., Kang, G. and Houpt, E.R. (2016). Optimization of quantitative PCR methods for enteropathogen detection. PLoS ONE 11, e0158199.

Llewellyn, S., Inpankaew, T., Nery, S. V., Gray, D. J., Verweij, J. J., Clements, A. C., Gomes, S. J., Traub, R. and McCarthy, J. S. (2016). Application of a multiplex quantitative PCR to assess prevalence and intensity of intestinal parasite infections in a controlled clinical trial. PLoS Neglected Tropical Diseases 10, e0004380.

Mejia, R., Vicuna, Y., Broncano, N., Sandoval, C., Vaca, M., Chico, M., Cooper, P. J. and Nutman, T. B. (2013). A novel, multi-parallel, real-time polymerase chain reaction approach for eight gastrointestinal parasites provides improved diagnostic capabilities to resource-limited at-risk populations. American Fournal of Tropical Medicine and Hygiene 88, 1041-1047. Meurs, L., Brienen, E., Mbow, M., Ochola, E. A., Mboup, S., Karanja, D. M., Secor, W.E., Polman, K. and van Lieshout, L. (2015). Is PCR the next reference standard for the diagnosis of Schistosoma in stool? A comparison with microscopy in Senegal and Kenya. PLoS Neglected Tropical Diseases 9, e0003959.

Niesters, H. G. (2002). Clinical virology in real time. Fournal of Clinical Virology 25 (Suppl. 3), S3-S12.

O'Connell, E. M. and Nutman, T. B. (2016). Molecular diagnostics for soil-transmitted helminths. American Fournal of Tropical Medicine and Hygiene 95, 508-513.

Obeng, B. B., Aryeetey, Y. A., de Dood, C. J., Amoah, A. S., Larbi, I. A., Deelder, A. M., Yazdanbakhsh, M., Hartgers, F. C., Boakye, D. A., Verweij, J. J., van Dam, G. J. and van Lieshout, L. (2008). Application of a circulating-cathodic-antigen (CCA) strip test and realtime PCR, in comparison with microscopy, for the detection of Schistosoma haematobium in urine samples from Ghana. Annals of Tropical Medicine \& Parasitology 102, 625-633.

Pillay, P., Taylor, M., Zulu, S. G., Gundersen, S. G., Verweij, J. J., Hoekstra, P., Brienen, E. A., Kleppa, E., Kjetland, E.F. and van Lieshout, L. (2014). Real-time polymerase chain reaction for detection of Schistosoma DNA in small-volume urine samples reflects focal distribution of urogenital Schistosomiasis in primary school girls in KwaZulu Natal, South Africa. American Fournal of Tropical Medicine and Hygiene 90, 546-552.

Platts-Mills, J. A., Gratz, J., Mduma, E., Svensen, E., Amour, C., Liu, J., Maro, A., Saidi, Q., Swai, N., Kumburu, H., McCormick, B. J., Kibiki, G. and Houpt, E. R. (2014). Association between stool enteropathogen quantity and disease in Tanzanian children using TaqMan array cards: a nested case-control study. American fournal of Tropical Medicine and Hygiene 90, 133-138.

Pullan, R. L., Smith, J. L., Jasrasaria, R. and Brooker, S. J. (2014). Global numbers of infection and disease burden of soil transmitted helminth infections in 2010. Parasites \& Vectors 7, 37.

Tahapary, D. L., de Ruiter, K., Martin, I., van Lieshout, L., Guigas, B., Soewondo, P., Djuardi, Y., Wiria, A. E., Mayboroda, O. A., Houwing-Duistermaat, J.J., Tasman, H., Sartono, E.,
Yazdanbakhsh, M., Smit, J. W. and Supali, T. (2015). Helminth infections and type 2 diabetes: a cluster-randomized placebo controlled SUGARSPIN trial in Nangapanda, Flores, Indonesia. BMC Infectious Diseases 15, 133.

Taniuchi, M., Sobuz, S. U., Begum, S., Platts-Mills, J. A., Liu, J., Yang, Z., Wang, X. Q., Petri, W. A., Jr., Haque, R. and Houpt, E. R. (2013). Etiology of diarrhea in Bangladeshi infants in the first year of life analyzed using molecular methods. Fournal of Infectious Diseases 208, 1794-1802.

ten Hove, R. J., Verweij, J. J., Vereecken, K., Polman, K., Dieye, L. and van Lieshout, L. (2008). Multiplex real-time PCR for the detection and quantification of Schistosoma mansoni and S. haematobium infection in stool samples collected in northern Senegal. Transactions of the Royal Society of Tropical Medicine and Hygiene 102, 179-185.

Utzinger, J., Brattig, N.W., Leonardo, L., Zhou, X.N. and Bergquist, R. (2015). Progress in research, control and elimination of helminth infections in Asia. Acta Tropica 141, 135-145.

van Lieshout, L. and Roestenberg, M. (2015). Clinical consequences of new diagnostic tools for intestinal parasites. Clinical Microbiology and Infection 21, 520-528.

van Lieshout, L. and Yazdanbakhsh, M. (2013). Landscape of neglected tropical diseases: getting it right. The Lancet Infectious Diseases 13, 469-470.

Verollet, R. (2008). A major step towards efficient sample preparation with bead-beating. BioTechniques 44, 832-833.

Verweij, J. J. (2014). Application of PCR-based methods for diagnosis of intestinal parasitic infections in the clinical laboratory. Parasitology 141, 1863-1872.

Verweij, J. J. and Stensvold, C. R. (2014). Molecular testing for clinical diagnosis and epidemiological investigations of intestinal parasitic infections. Clinical Microbiology Reviews 27, 371-418.

Verweij, J. J., Oostvogel, F., Brienen, E. A., Nang-Beifubah, A., Ziem, J. and Polderman, A. M. (2003a). Short communication: prevalence of Entamoeba histolytica and Entamoeba dispar in northern Ghana. Tropical Medicine \& International Health 8, 1153-1156.

Verweij, J. J., Schinkel, J., Laeijendecker, D., van Rooyen, M. A., van Lieshout, L. and Polderman, A. M. (2003b). Real-time PCR for the detection of Giardia lamblia. Molecular and Cellular Probes 17, 223 225 .

Verweij, J. J., Blange, R. A., Templeton, K., Schinkel, J., Brienen, E. A., van Rooyen, M. A., van Lieshout, L. and Polderman, A. M. (2004). Simultaneous detection of Entamoeba histolytica, Giardia lamblia, and Cryptosporidium parvum in fecal samples by using multiplex realtime PCR. Fournal of Clinical Microbiology 42, 1220-1223.

Verweij, J. J., Brienen, E. A., Ziem, J., Yelifari, L., Polderman, A. M. and Van Lieshout, L. (2007a). Simultaneous detection and quantification of Ancylostoma duodenale, Necator americanus, and Oesophagostomum bifurcum in fecal samples using multiplex real-time PCR. American fournal of Tropical Medicine and Hygiene 77, 685-690.

Verweij, J. J., Mulder, B., Poell, B., van Middelkoop, D., Brienen, E. A. and van Lieshout, L. (2007b). Real-time PCR for the detection of Dientamoeba fragilis in fecal samples. Molecular and Cellular Probes 21, 400-404.

Verweij, J. J., Canales, M., Polman, K., Ziem, J., Brienen, E. A., Polderman, A. M. and van Lieshout, L. (2009). Molecular diagnosis of Strongyloides stercoralis in faecal samples using real-time PCR. Transactions of the Royal Society of Tropical Medicine and Hygiene 103, 342-346.

Wiria, A. E., Prasetyani, M. A., Hamid, F., Wammes, L. J., Lell, B., Ariawan, I., Uh, H.W., Wibowo, H., Djuardi, Y., Wahyuni, S., Sutanto, I., May, L., Luty, A. J., Verweij, J. J., Sartono, E., Yazdanbakhsh, M. and Supali, T. (2010). Does treatment of intestinal helminth infections influence malaria? Background and methodology of a longitudinal study of clinical, parasitological and immunological parameters in Nangapanda, Flores, Indonesia (ImmunoSPIN Study). BMC Infectious Diseases 10, 77.

Wiria, A.E., Hamid, F., Wammes, L. J., Kaisar, M. M., May, L., Prasetyani, M. A., Wahyuni, S., Djuardi, Y., Ariawan, I., Wibowo, H., Lell, B., Sauerwein, R., Brice, G. T., Sutanto, I., van Lieshout, L., de Craen, A. J., van Ree, R., Verweij, J. J., Tsonaka, R., Houwing-Duistermaat, J. J., Luty, A. J., Sartono, E., Supali, T. and Yazdanbakhsh, M. (2013). The effect of three-monthly albendazole treatment on malarial parasitemia and allergy: a householdbased cluster-randomized, double-blind, placebo-controlled trial. PLoS ONE 8, e57899. 